\title{
Demographic theory and population ethics
}

\author{
Martin Kolk ${ }^{1}$
}

This manuscript is a preprint of the book chapter "Demographic theory and population ethics" to be published in 2021 in Oxford Handbook of Population Ethics edited by in Gustaf Arrhenius, Krister Byqvist, Tim Campbell, \& Elizabeth Finneron-Burns, by Oxford University Press, Oxford.

\section{Abstract}

Demographic theory is concerned with how population systems regulate themselves given available resources and external shocks to population size. This chapter provides an overview of demographic theory, focusing specifically on relationships between population size, population growth, and welfare. It then discusses four implications of demographic theory for population ethics. Speaking broadly, these four implications concern (1) the overreliance by some population ethicists on Malthusian assumptions about the average welfare of population declining with increasing population size, (2) the likelihood of certain hypothetical scenarios that feature in thought experiments used in population ethics, (3) the prioritization of extinction risks by population ethicists, and (4) the patterns of intergenerational and intertemporal inequality that population ethicists may anticipate over the long run. The chapter closes with a discussion of demographic theory in relation to historical and future demographic change.

${ }^{1}$ Demography Unit, Stockholm University, Centre for Cultural Evolution, Stockholm University, and the Institute for Future Studies, Stockholm, martin.kolk@sociology.su.se 


\section{Introduction}

Population ethics is concerned with demography in the sense that the analytical objects of interest are populations ${ }^{1}$. However, demographic theory, which explores theoretically when, how and why populations grow, based on empirically observed patterns, has until now played only a minor role in population ethics. Similarly, debates about population dynamics among demographers have seldom been concerned with ideas and concepts in population ethics.

In this chapter, I will give a brief outline of how population size, population growth, and welfare, mutually affect each other. I will discuss how population growth responds to welfare, as welfare is an important concept in population ethics. I will discuss population homeostasis (the dynamics of a system which maintains a population at a steady population size), with a focus on resource dependent homeostatic mechanisms. I will discuss both negative relationships between population size and welfare, and refer to such relationships as "Malthusian" (after Thomas Malthus), and positive relationships between population size and welfare and refer to them as "Boserupian" (after the economist Ester Boserup). I will then consider four implications of population homeostasis for population ethics: First, Malthusian assumptions about average welfare declining with increasing population size are sometimes implicit in the population ethics discourse, and ethicists may want to explore alternative assumptions, one of which I shall discuss in detail below. ${ }^{2}$ Second, a nuanced understanding of demographic theory may help to understand if the imagined scenarios featured in thought experiments commonly used in the arguments presented by population ethicists are unlikely, or even nearly impossible empirically. If an ethical theory produces paradoxes and implausible conclusions that are unlikely given demographic theory, they may be less of a concern (both practically and theoretically) than other implications that are empirically more likely given demographic theory. Third, demographic theory suggests that human extinction from gradual processes is highly unlikely, and that therefore those concerned with mitigating extinction risk should consider focusing on risks from sudden discrete events. Fourth, demographic theory may also inform population ethicists if certain population scenarios are plausible only in the short term, or if they are plausible over longer

\footnotetext{
${ }^{1}$ Throughout this text I will use the term 'population' and 'population size' to refer to the number of living individuals at a single time. The geographical area or definition will be left unspecified, and I will occasionally use 'population density' and 'population size' interchangeably as for a certain (closed) area such as Earth - the two concepts are identical.

${ }^{2}$ See also Dasgupta and Dasgupta (this volume), as well as Dasgupta (1998).
} 
time scales. One type of scenario that I will consider in this area, and that has been a topic of concern among some population ethicists, involves increasing intergenerational inequality. Finally, I will discuss demographic theory in relation to historical and future demographic change.

Before proceeding, it will be useful to set out some background assumptions. One important assumption concerns my use of the term 'welfare'. Although an individual's welfare is arguably not the same as her living standard or the wage that she earns, for the purpose of my discussion, I will use the average wage, or living standard, in the population as a proxy for average welfare. An individual's resources are predictive of individual behaviour, and as such have explanatory power for a demographic system (for example the theoretical relationships described in this chapter). However, unlike average welfare, total welfare (the product of average welfare and population size) is not a dimension that explains why individuals in a society act the way they do, at least for the models that I will discuss. Thus, in this chapter I will focus mostly on the average welfare of (an individual in) a population, and how it relates to population size and population growth.

I will assume that the populations in my examples are homogenous in the sense that the average welfare (wage, living standard) is the same as the welfare (wage, living standard) of any individual in the population. Throughout this chapter, the time perspective will be comparatively large and encompass multiple generations of humans. When I use the term 'long-term' I refer to at least 3+ generations, a longer perspective than what is assumed in most governmental and scientific projections of population size. The determinants of population growth, mortality, and fertility in a shorter time perspective are different and are not the focus of this chapter.

Finally, it is important to note that demographic theory is descriptive, not normative or evaluative. It is concerned with empirical phenomena such as births and deaths that are easy to measure and define across widely different contexts and times. It is concerned with describing populations as systems in which population change and population size are endogenously related, and finding empirical patterns in how and why populations change. Population equilibriums in demographic theory are therefore different from calculations of optimal population size, which are explicitly evaluative, and which usually aim to find the population size that maximizes (either average or total) welfare. ${ }^{3}$ However, demographic theory may still be used to inform population ethics. For example, inquiries

\footnotetext{
${ }^{3}$ For discussion of optimal population size, see Greaves (this volume)
} 
into optimal population size at a time, as well as projections of cumulative welfare across a large number of generations, will (assuming certain real-world constraints) have to make assumptions about how population size at a time is related to welfare, how welfare is related to population growth, and how population size at a time is related to population growth at later times. Demographic theory can help inform these assumptions.

\section{Exponential growth, economic demography and population bomeostasis}

A fundamental characteristic of human populations is that they grow and decline exponentially. This creates the potential for very quick growth and decline over multiple generations. Most populations will, given favourable circumstances, quickly expand at such a quick rate that when one shifts to a longer time perspective, there must be some other factor (e.g. shortage of resources, or an awareness that the population needs to be regulated) holding back growth. For example, the French-speaking population in Quebec had population growth rates from natural growth of around $2 \%$ for several centuries which increased the population several hundred times starting from the $17^{\text {th }}$ century (Charbonneau, Desjardins, Légaré, \& Denis, 2000). ${ }^{4}$

That population size eventually stabilizes after a period of growth is a phenomenon that is repeatedly observed in both animal and human populations. This realization goes back to Malthus and served as inspiration for what Darwin called the "struggle for existence". Like exponential growth, negative exponential growth is also powerful in that it can decrease population very quickly. Even a population in which no individual ever dies would quickly stop increasing if each woman gave birth to less than two children over her (infinite) life, as each new generation would be smaller than the previous one. ${ }^{5}$ For example, a population

\footnotetext{
${ }^{4}$ Natural growth refers to population changes arising from births and deaths, not taking migration into account.

${ }^{5}$ Demographers use the concept of Net Reproductive Rate (NRR), which is typically defined from only a female perspective, and is the average number of surviving daughters of a woman, at a given a level of mortality and fertility of the woman. If the NRR is larger than 1 a population will grow, and if it is smaller than 1 it will shrink. For example, an NRR of 1 would arise if women on average gave birth to two children, there is a sex ratio of 0.5 , and no woman dies before the end of her childbearing age.
} 
in which each woman gives birth to only one child would stabilize at twice the original size in a population where there are no deaths. ${ }^{6}$

Any fast-growing human population will stop growing rapidly at some point due to the nature of exponential growth. A world population growth rate of $2.2 \%$ was observed in the 1960s. If this rate were held constant for a population (such as Earth's) for 500 years, the population would be 53,143 times larger than at the beginning of the 500 year period. ${ }^{7}$ Clearly, this would not actually happen. Although populations can sustain such growth over the short term, such growth rates inevitably come to an end. A useful interpretation of the demographic transition, the shift from a high fertility-high mortality society, to a society with reduced mortality and consequently high population growth, to a low fertilitylow mortality society, can be seen as an inescapable outcome of a process in which exogenous factors such as improved technology reduce mortality permanently. The demographic transition is then a (homeostatic) way for a society to regain population balance and escape unsustainable population growth (Wilson \& Airey, 1999). A demography theorist's definition of 'overpopulation' can be said to be the population size for which population growth turns negative.

In a homeostatic population model, population growth must be related in some way to population size. That populations are bounded by available resources and that human population growth is positive when resources are abundant and negative when resources are scarce were key insights of Malthus in the $18^{\text {th }}$ century. ${ }^{8}$ A Malthusian relationship is central in ecological models applicable to all species, and there is clear evidence that such mechanisms regulate population size in historical agricultural and hunter-gatherer societies (Lee, 1987). This is an example of population homeostasis, in which population growth responds to population size, in this case through a positive association between resource

\footnotetext{
${ }^{6}$ This results from an NRR of 0.5 , as the equation $a+a r+a r^{2}+a r^{3}+a r^{4}+\cdots=\sum_{k=0}^{\infty} a r^{k}=\frac{a}{1-r}$, for $|r|<1$. gives a sum of 2 if $\mathrm{a}$ is equal to 1 and $\mathrm{r}$ equal to 0.5. This geometric series represents a cumulative population when every new generation is half the size of the previous one.

${ }^{7}$ After 2000 years there would only be enough matter on Earth for 1 gram per person.

${ }^{8}$ However, the idea of a positive relationship between the number of people and wealth were common in many societies long before Malthus, and this idea was part of a broader scientific discourse in $18^{\text {th }}$ century Europe (Hutchinson, 1967).
} 
availability and population growth and a negative association between resource availability and population size. ${ }^{9}$

Although a Malthusian model has explanatory power, it cannot explain how human population size has increased from millions to billions in the last few thousand years. In the last 10,000 years the global population has not only grown exponentially, but the growth rate itself has until recently grown exponentially (Livi-Bacci, 2007). This seems to imply that there must have been some development of human culture that has allowed an increasingly large population size over time, breaking a strict population homeostasis.

It is plausible that an increasing population size or density can also be associated with increasing average welfare and population growth. ${ }^{10}$ Higher population density encourages specialization, which can be an efficient way to organize labour, encouraging higher human capital. Higher population density may also increase the demand for new technology. ${ }^{11}$ Transportation, communication, and access to ideas would also increase with population density. Similarly, if novel ideas and innovations appear largely by chance, more people implies more novel ideas and innovation. A larger population can also maintain more knowledge at a given time (S. Ghirlanda, Enquist, \& Perc, 2010; Lehmann, Aoki, \& Feldman, 2011). Throughout the $19^{\text {th }}$ century, several political economists criticized Malthus and suggested that increasing population pressure might stimulate innovation that could counter diminishing returns (Hutchinson, 1967, pp. 152-202). ${ }^{12}$ The economist Ester Boserup examined the relationship between population density and innovation in SubSaharan Africa (Boserup, 1965, 1981), and found that higher population density on average

\footnotetext{
${ }^{9} \mathrm{~A}$ stable population equilibrium is when all individuals are living at subsistence level, but it is possible that the function between welfare and population growth is different, and that for example societies would regulate reproduction so that a population equilibrium would take place at welfare levels above the subsistence minimum.

${ }^{10}$ Note that throughout this chapter I will treat population density and population size as analogous concepts. In the short-term populations will likely resort to migration when facing resource constraints, but in the longer run the destination population will face similar demographic pressures. At equilibrium population density and population size can then be treated as analogously. Most obviously Earth itself is for the foreseeable future a closed population system, in which population density and population size are identical. However, migration remains an important practical concern when attempting to test population theories using empirical data.

${ }^{11}$ When using technology throughout the article it is defined in very broad terms as any cultural institution, idea, capital investment, or way of live, which is associated with productivity. As such, it also reflects institutional and cultural change broadly and not only technical engineering inventions.

12 Thomas Sadler in 1830, Friedrich List in 1841, and John McChulloch in 1846, all clearly and forcefully argued that better innovation and better agricultural techniques could and would be applied to counter diminishing returns (Hutchinson, 1967).
} 
increased the adoption of better agricultural techniques and technology, and increased both average welfare and population growth.

To illustrate both Boserupian (a positive dependency between welfare and population growth) and Malthusian relationships (a negative dependency), consider the population of medieval Europe. This population varied around 50 million inhabitants between 1000 and 1500 C.E. (Livi-Bacci, 1999). If, during this time, the population had instead been over 700 million, similar to what it was in the 2010s, average welfare would have been very low. If, however, the population had been only 10,000, it seems clear that it would not have been able to maintain the specialization and technology that Europe had during the middle ages, and that all the existing spare land and abundant resources would have been of relatively little use. With such a low population size, average welfare would also have been low. A higher average living standard (welfare) and plausibly higher population growth, would lie somewhere in-between the two extremes just considered (10,000 and 700 million). Accounts of the economic and demographic history of Europe in the middle ages suggest that Europe was close to its maximum population size given available resources around 1340, before the plague reduced the population (e.g. Livi-Bacci, 1999). The large population size in Europe before the plague resulted in that much sub-standard land and labourintensive cultivation. Average living standards would have been higher at a lower population density. This implies that for some hypothetical population, between 50 million and 10,000 people, the average living standard (welfare) would have been higher than at either 50 million or 10,000 , though exactly at what size is very hard to estimate. It also implies that at the lower bound of that population range, we should over time expect an increasing population size and high average welfare, while at the upper bound (and above) we should expect the opposite.

A homeostatic Malthusian model in which population growth is negatively correlated with population size, and in which population growth is high at low population size, and negative at higher population sizes, is illustrated in figures 1-3. A key assumption of a Malthusian model is that higher population size is associated with lower average welfare (figure 1). The relationship between average welfare and population growth is assumed to be positive as vital rates (births and deaths) respond to greater abundance of resources (figure 2). This gives a negative relationship between population size and population growth (figure 3). The point at which population growth is about 0 is the equilibrium population size, around which a population would oscillate. In an animal population this would be the carrying capacity of the population, and this is also plausible for human 
populations. Technological growth can be seen as an exogenous process which would gradually shift the line in figure 1 upwards, resulting in a period of population growth, followed by oscillation around a new higher equilibrium population size. Moreover, both industrial and pre-industrial human populations may regulate reproduction through a Malthusian relationship that would not necessarily result in a population on the brink of population collapse where average welfare (wages) are close to a subsistence minimum. This was likely the case in pre-industrial Europe as, for example, marriages responded negatively to increasing population size and decreasing average welfare.

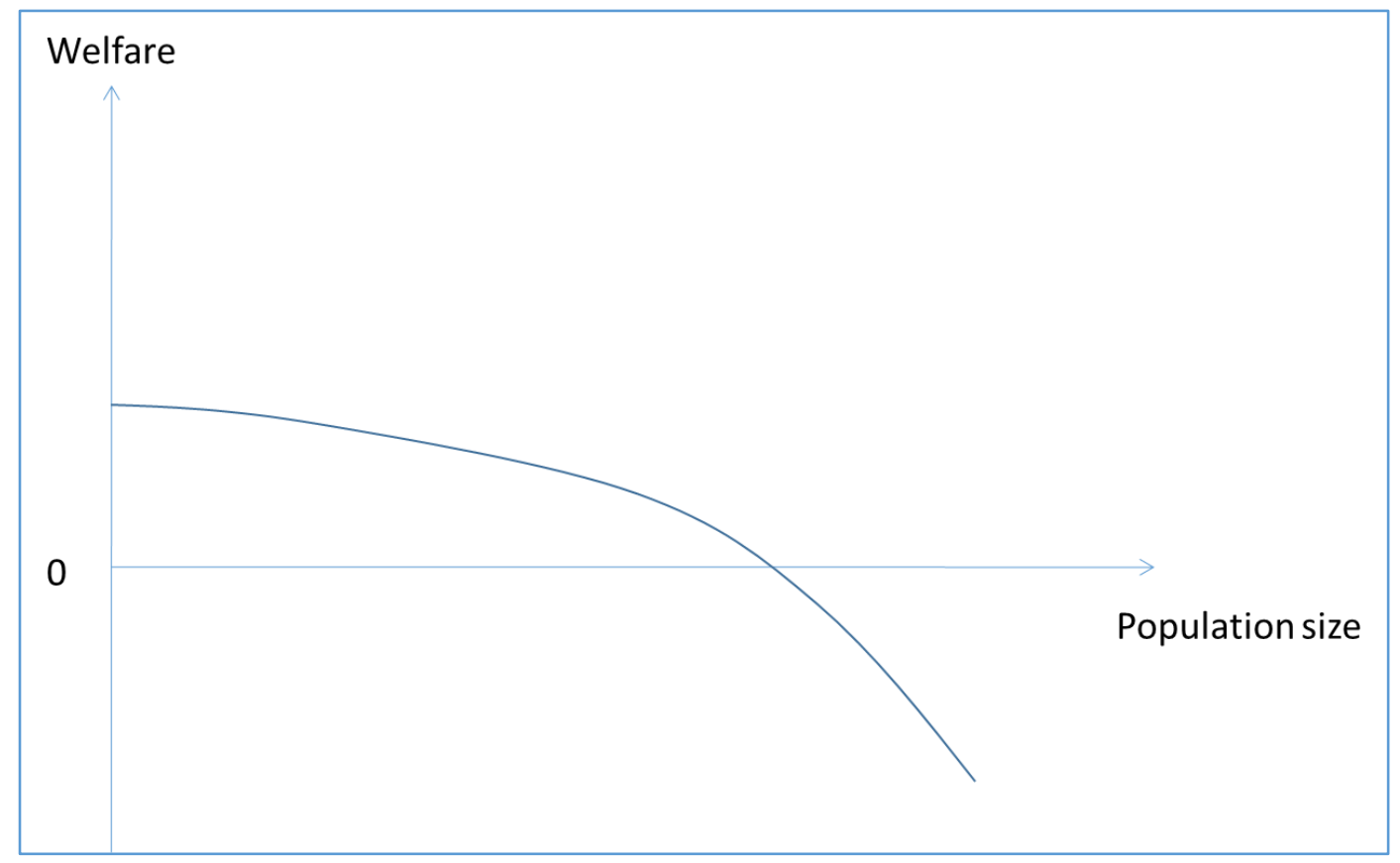

Figure 1: Malthusian relationship between population size and welfare 


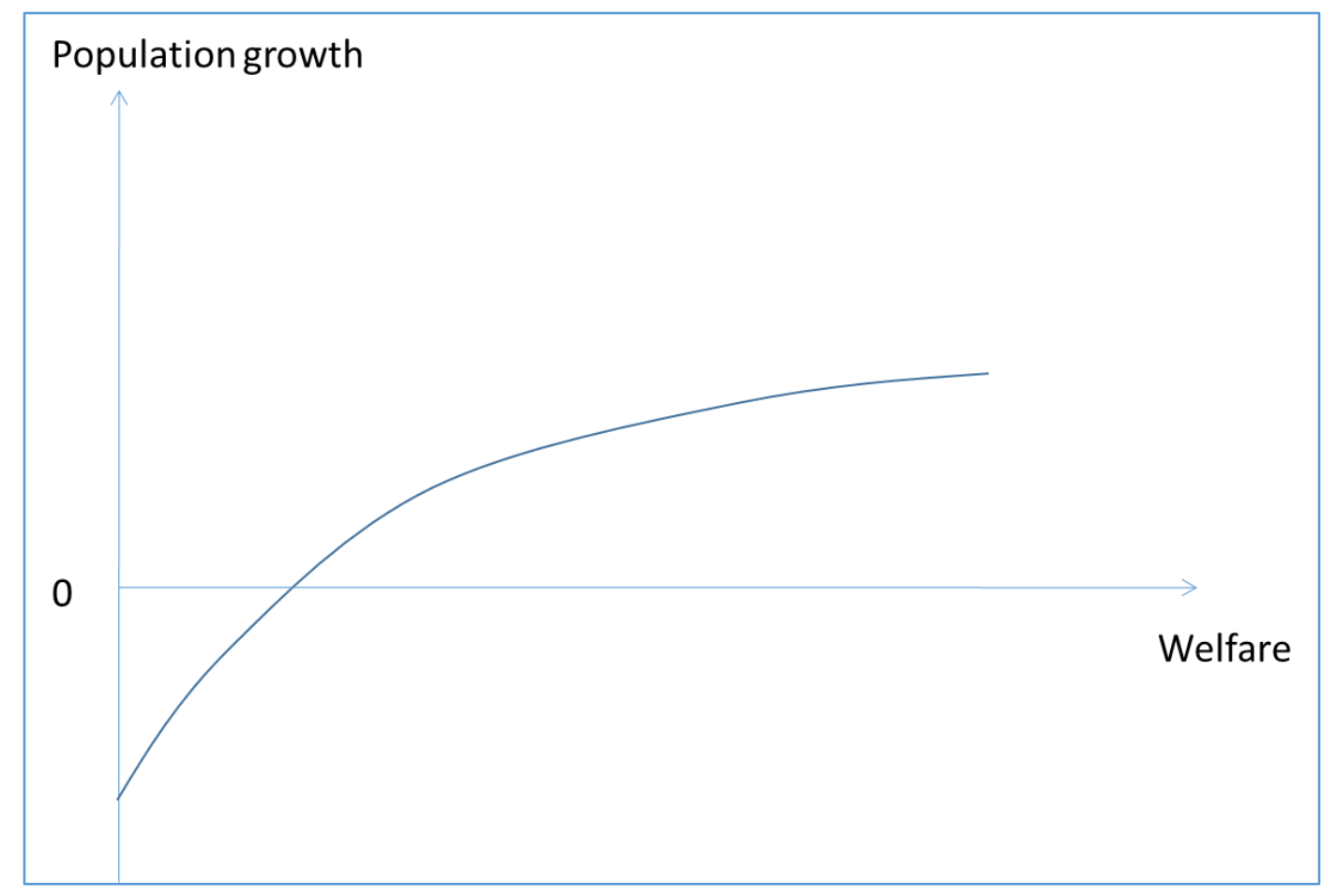

Figure 2: Malthusian relationship between welfare and population growth

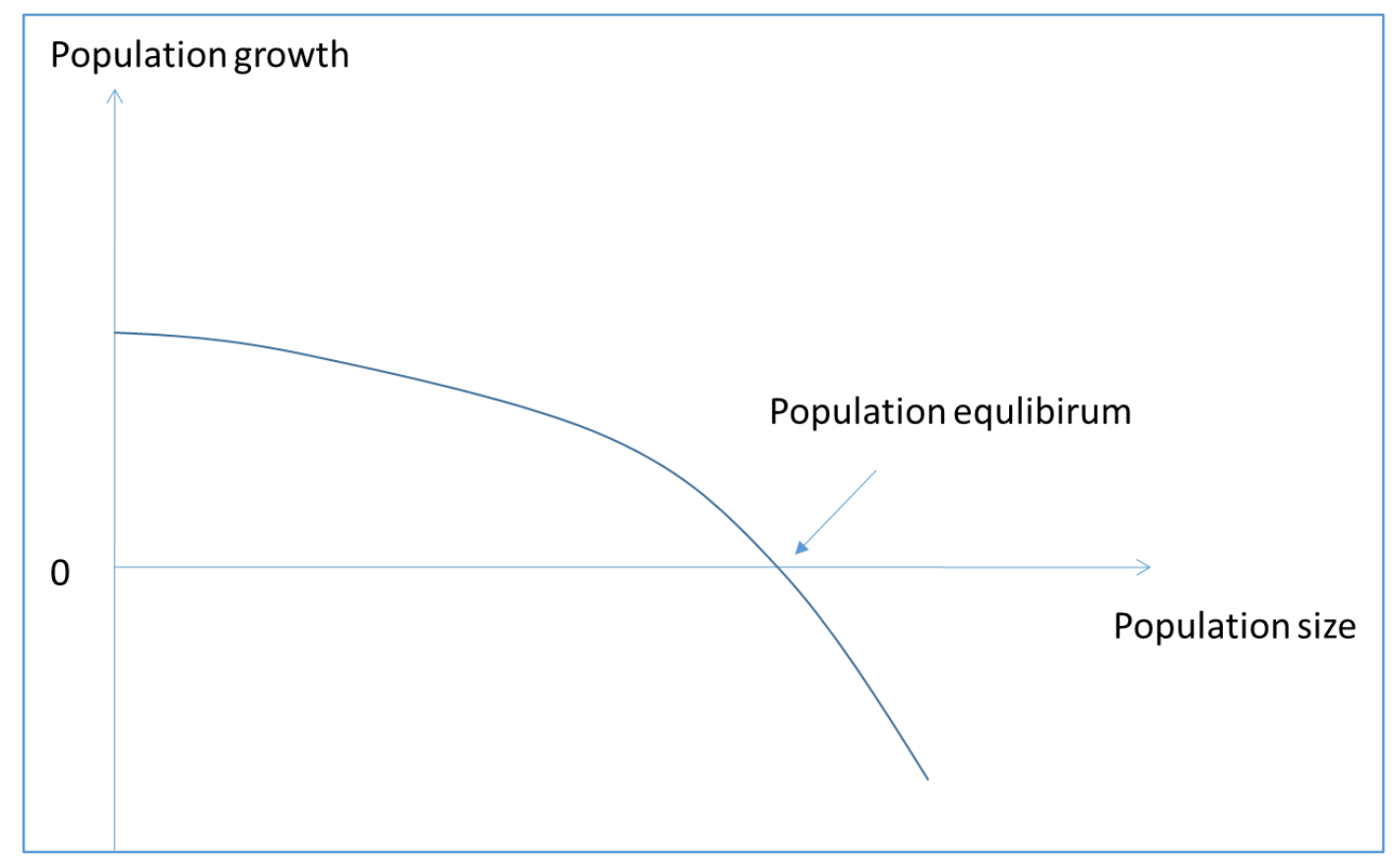

Figure 3: Relationship between population size and population growth in a Malthusian model. 
It is, as discussed earlier, likely that for some population levels an increasing population or higher population density would increase average welfare. If such a Boserupian relationship holds for any population size (as in figure 4) this would create a Boserupian model with population size increasing toward infinity. Suppose, on the other hand, that such a Boserupian relationship is dominant at lower population sizes (figure 4), but that ecological pressures result in a negative (Malthusian) relationship at higher population sizes (as in figure 2). Then the relationship between population growth and population size would instead be roughly curvilinear as in figure $5 .{ }^{13}$ This figure illustrates a combined Malthusian and Boserupian relationship at a given technological level, but it is possible that such processes would also increase the equilibrium population size over time. Boserupian processes such as increased intensification of land or adaptation spurred by increasing population density may stimulate technological growth and allow higher and higher equilibrium population sizes. It is easy to construct such a model in which population size will increase forever. However, given the nature of exponential population growth, a population cannot increase infinitely, and at some point each new individual must have a negative effect on the average welfare in a population. This implies that at some population size the relationship between population and average welfare must turn negative, and one would obtain a relationship roughly like what is described in figure 5. Like a Malthusian model, such a combined Boserupian-Malthusian model has an equilibrium population size around which the population would eventually oscillate. However, unlike a Malthusian model, the combined Boserupian-Malthusian model implies that at lower population sizes, increasing population size would increase population growth.

\footnotetext{
${ }^{13}$ It is not necessary to make any assumptions about the functional form of the relationships in any of figures 1-5 except that below some population level, an additional person increases welfare monotonically, and at above that population level there is instead a monotonic decline for each additional person. It also seems reasonable that population growth is above 0 for a very tiny population (though this is not necessary, there are examples on animal species that face extinction if population size falls below a certain level; a famous historical case is the North American passenger pigeon). There must also be some population level for which population growth turns negative, as the model would otherwise predict a population size that would move towards infinity.
} 


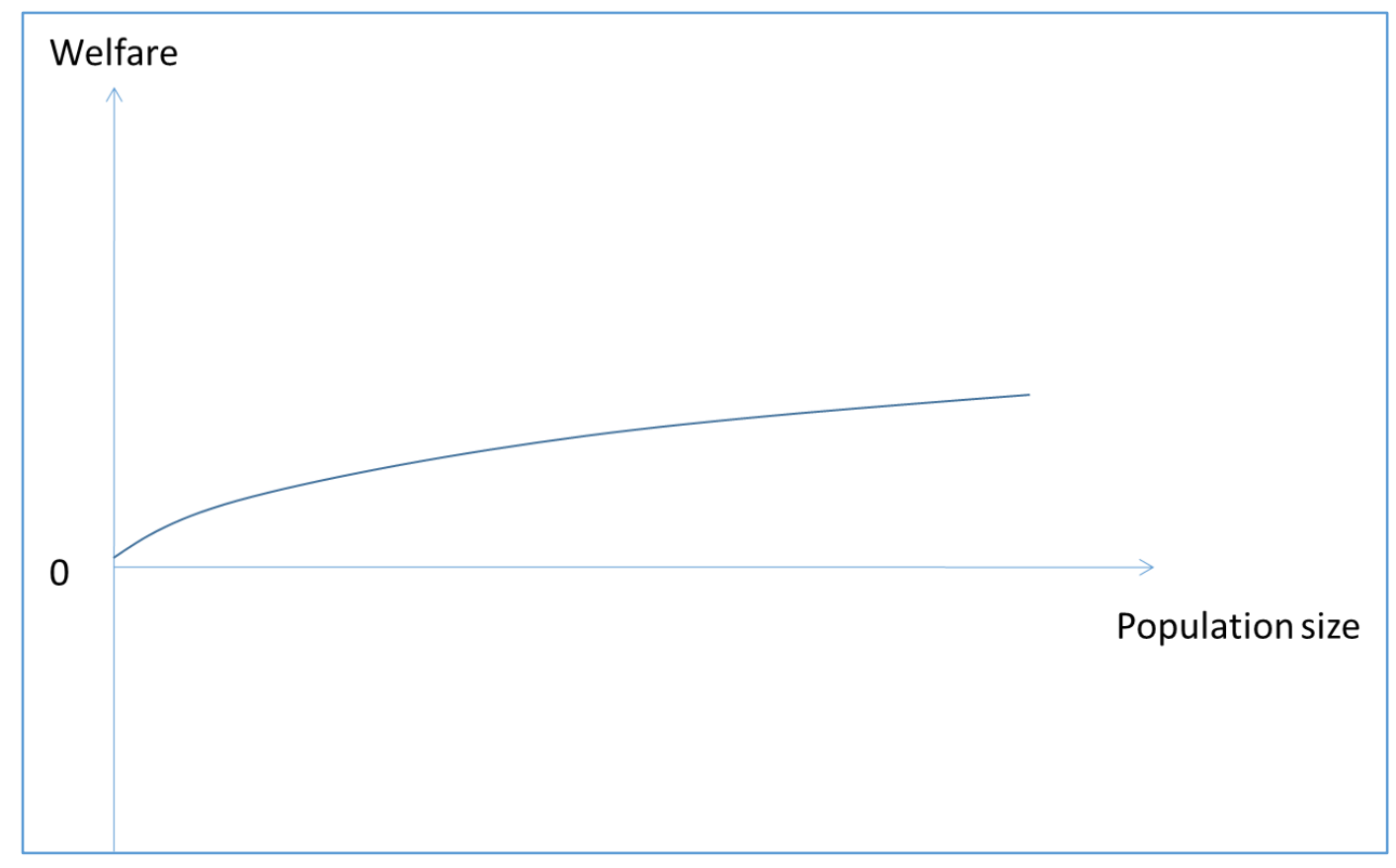

Figure 4: Boserupian relationship between population size and welfare

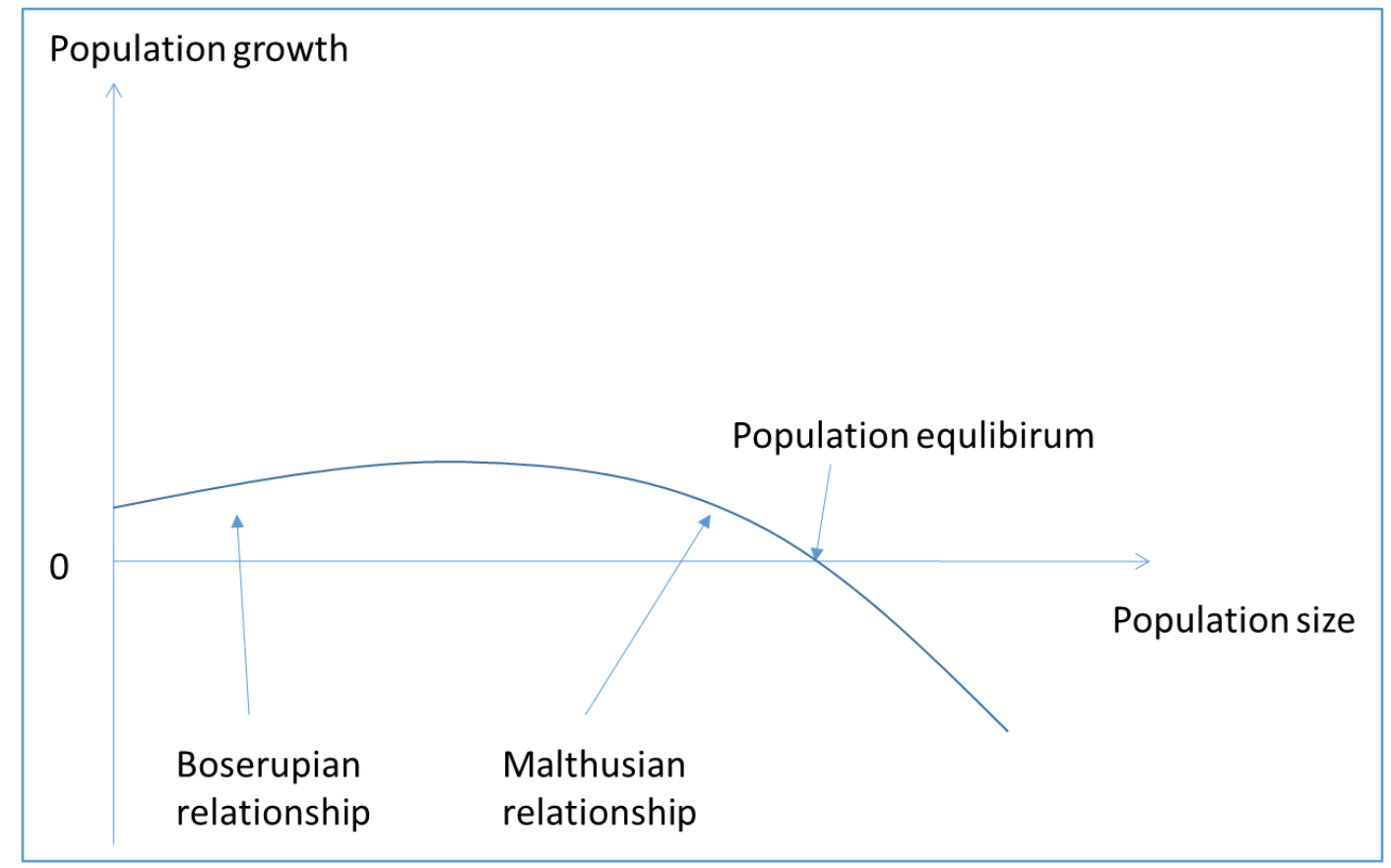

Figure 5: Combined Boserupian and Malthusian relationship between population growth and population size 
Researchers have demonstrated that in historical European populations a larger population decreased wages as in Figure 1 (Galloway, 1988; Lee \& Anderson, 2002). Researches have also found that lower (real) wages reduced population growth as in figure 2 (e.g. Bengtsson, Campbell, \& Lee, 2003; Lee, 1987; Tsuya, Feng, Alter, \& Lee, 2010). In preindustrial populations, it is clear that the relationship between population and welfare was Malthusian (as in figure 3), and for most of human history it seems clear that human population size was regulated by resource-dependent homeostatic mechanisms (Lee, $1987)^{14}$. However, equally striking is the great, though gradual, increase in global population size over time. The rapid increase in population size during and after the industrial revolution is particularly striking.

One possible explanation for this rapid increase is that technological growth is exogenous, that human innovation increased largely independent of population size or density, and that this increase in technology resulted in increased productivity, allowing higher population size. Such a relationship could be illustrated by exogenous shifts to the right in the curve shown in figure 3, allowing higher and higher equilibrium population sizes. However, both theory and empirical evidence (e.g. Boserup, 1965) suggest that a growing population size itself could stimulate adoption of innovative behaviour, thereby increasing average welfare. If this is the case, technology, and by extension population growth, is under some circumstances positively correlated with population size. The broad characteristics of such a relationship combined with a Malthusian relationship at higher population sizes are described in figure 5 .

Simple Boserupian models will result in both technology and population size both growing at an increasingly rapid pace forever (e.g. the combination of figure 2 and 4 ) if there is no Malthusian mechanism. However as discussed earlier, population growth has to be bounded by some factor eventually. Researchers have created more sophisticated models combining Boserupian and Malthusian processes (Chu \& Tsai, 1998; Stefano Ghirlanda \& Enquist, 2007; S. Ghirlanda et al., 2010; Lee, 1986; Pryor \& Maurer, 1982; Simon, 1977). Such models include assumptions beyond those represented in figure $5 .{ }^{15}$ The relationship described in figure 5 has only two necessary assumptions; that for some population size

\footnotetext{
${ }^{14}$ Similar relationships underpin ecological models on animals where similar strong effects between resources and population growth are observed (Lee, 1987; Sibly \& Hone, 2002).

${ }^{15}$ Examples of such additional assumptions in the models are: population sizes necessary to maintain technology, technological knowledge gradually lost over time, and technological growth is made possible from any surplus of resources above what is necessary for pure subsistence.
} 
(given abundant resources) there is a positive effect of a larger population to welfare, and that at some much higher population size this relationship reverses.

\section{Implications of Demographic Theory for Population Ethics}

Above I discussed how population growth and population size mutual affect each other, which I refer to as demographic theory. In this section, I consider four implications of such relationships for population ethics.

The first implication concerns population ethicists' reliance on Malthusian assumptions. There is a (sometimes implicit) tradition in population ethics of assuming a negative relationship between average welfare and population size, following a Malthusian perspective. ${ }^{16}$ Sometimes the assumption is made only for the purpose of illustrating a theoretical point. However, arguments are sometimes driven by the assumption. Moreover, even when the assumption is adopted only for the purpose of illustration, this may reinforce belief in the assumption.

${ }^{16}$ See for example the following quotes from population ethicists.

In the quote below by Parfit (1984) he, a) takes a Malthusian relationship as an empirical fact in some contemporaneous societies, and b) then after first qualifying that a Malthusian relationship might not apply everywhere (in two sentences) c) proceeds to discuss the Malthusian case and implications of such a relationship (over 59 pages).

"The effect of population growth on existing people - My couple assume that the existence of an extra child would not on balance be worse for other people. In many countries, in many periods, this has been true. But in many other periods it has not been true. In these periods, if there had been more people, people would have been worse off. This is now true in many countries. In these countries, if the population grows, the quality of life will be lower than it would be if the population did not grow. These are the cases that I shall discuss" Parfit (1984, p. 382).

The quote below is the basis of a thought experiment introducing optimal population from Arrhenius and Campbell (2017):

"If the current generation continues to consume resources at the expense of future generations, and the population increases significantly, this could lead to an enormous population-ten billion people per generation-in which most people's lives are barely worth living. Suppose we could instead create a smaller population — around one billion people per generation — with very good lives. Which population would be better?” 
Broadly, one can distinguish two different approaches in population ethics when reasoning about the effect of population size on average welfare. The first approach, exemplified by Parfit (1984), Arrhenius (2011), and Broome (1996), compares hypothetical populations, and often the analytical treatment allows both a positive relationship between population size and welfare, as well as a negative relationship. However, typically the framing and examples assume a negative relationship. An example of this can be found in Parfit (1984). He considers a scenario in which the population of Earth expands in the next generation, driving the average welfare level down. A reason for the implicit Malthusian assumption is that the opposite case, of average welfare increasing with population size, does not involve trade-offs between population size and average welfare, which is a crucial feature in Parfit's discussion of many issues in population ethics. The second approach, illustrated by Dasgupta (1998), involves creating explicit models to calculate average welfare based on population size. Such models typically make and motivate Malthusian relationships between average welfare and population size.

The exclusive focus on Malthusian assumptions is problematic insofar as there are alternative assumptions and perspectives (e.g. Boserupian) that one could assume. This suggests that having a thorough understanding of demographic theory, and both Malthusian and non-Malthusian perspectives in population ethics, may clarify implicit assumptions in population ethics and may open up new avenues of research. Population ethicists should not be too confident in the assumption that, in any real-world scenario, expanding the population would drive down average welfare.

The second implication concerns the likelihood of the scenarios that are described in thought experiments intended to elicit intuitions about the comparative goodness of different populations. If a certain population axiology, or ethical theory, entails some implausible conclusion, for example that a very large population with lives only barely worth living would be very good, or better than a smaller population with much higher average welfare, then this may seem like a powerful objection to the theory. However, if the existence of such a large population is very unlikely given demographic theory, then the fact that the theory has such an implausible implication may be less of a concern than other theoretical implications regarding populations that are empirically more likely to exist given demographic theory. This point may be relevant for what we should do when we are uncertain which ethical theory is the true one. It may be that we should have more credence, or perhaps give more weight, to theories that produce paradoxes or implausible conclusions only in far out (but logically possible) cases than to theories that generate 
paradoxes or implausible conclusions in scenarios that are more likely given demographic theory (See, e.g., Bykvist, this volume).

Insofar as thought experiments comparing different populations are to have application in the real world, the shape of the function between population size and welfare is relevant. As we saw, a common assumption in thought experiments is a Malthusian relationship between high population size and lower welfare. In many cases researchers also assume a monotonic Malthusian relationship for any population size, and present examples with the highest welfare in populations with only a single individual. A Malthusian population equilibrium where the population size is close to subsistence levels, is probably what Parfit (1984) had in mind when he described a very large population with very low welfare (lives barely worth living) in his illustration of "The Repugnant Conclusion". He illustrates this relationship with a figure representing different populations, a smaller population with very high average welfare, and a much larger population with very low welfare. This figure conveys the same relationship between population size and average welfare as the relationship represented in figure 1 above (Parfit, 1984, p. 388).

However, demographic theory suggests that a population consisting of many "lives barely worth living" or "lives not worth living" is an unstable and short-term deviation from a population equilibrium ${ }^{17}$. According to demographic theory, population size will revert to intermediate equilibrium size in cases with very high and very low welfare. In a Malthusian model, the inevitable result of adding individuals when average welfare is very low will be negative future population growth. Enormous populations with either negative welfare or very low positive welfare are thus unsustainable. The scenario that Parfit describes is highly unlikely from the standpoint of demographic theory. ${ }^{18}$ The objection against certain theories, such as total utilitarianism, that they imply the Repugnant Conclusion may therefore be less powerful than it initially seems, and we may give less weight to this objection when deciding what credence to assign to theories like total utilitarianism in contexts involving evaluative and normative uncertainty.

\footnotetext{
${ }^{17}$ They will be unstable if "lives not worth living" are defined as truly dreadful lives where resources are insufficient for subsistence needs. If one also considers many lives not worth living where people have meager but not completely insufficient resources, a Malthusian model may instead predict a population where nearly all lives would be considered not worth living.

${ }^{18}$ as he acknowledges (1984), p. 388.
} 
Demographic theory suggests that a population with high fertility preferences will move towards a situation with high population size, and low welfare. The equilibrium population size that results is higher, and average (as well as total) welfare is lower, than optimal population size derived from average (or total) view of the value of welfare. Thus, for populations with high fertility preferences, given unlimited reproductive rights, resource availability will regulate eventual population size.

A third implication of demographic theory concerns extinction risk. Resource-dependent homeostatic models imply that a population collapse, or drastic and rapid decrease in population size, results in strong population growth following the collapse. A temporary exogenous change in population size can therefore be quickly recovered from. Effects of population reduction on welfare are therefore also short-term. In addition, we know of the human past that absolute extinction of a population in a region is rare, consistent with demographic theory. ${ }^{19}$ Resource-dependent homeostatic models are central in basic ecological models of other species (Sibly \& Hone, 2002), though there are also ecological examples of inverse relationships for low population densities (Courchamp, Clutton-Brock, \& Grenfell, 1999). This has implications for assessing the risk of total population extinction, a topic of interest to population ethicists (e.g. Broome, 2010). If the welfare of future populations is not (or is only slightly) discounted, and if total (rather than average) welfare determines the value of a population, then human extinction entails a massive value loss. However, if homeostatic population models are correct, population extinctions are highly unlikely, at least where such extinctions would result from gradual processes such as climate change or environmental degradation. This excludes sudden discrete catastrophic impacts that kill an entire population at once, such as a gigantic asteroid impact. Those concerned about human extinction risk may therefore have reason to focus more on extinction risk from such sudden discrete events, as well as events caused by factors exogenous to the models discussed in this chapter.

\footnotetext{
${ }^{19}$ By 'absolute extinction', I mean that the population in an area declines to 0 , through vital rates alone, without outmigration, cultural assimilation, or replacement by other populations in the same area. While dramatic, seemingly non-recoverable, population reductions are common, complete extinction appears rare. Famous example such as the Norse population on Greenland where abandoned through migration, and only a few (very inhospitable) Polynesian islands appear to ever have been abandoned, or even more speculatively population died out. Examples of such islands are the Auckland, Kermadec, Norfolk, and Pitcairns islands which all at some point were depopulated, though this likely took place through migration.
} 
Finally, homeostatic population models also have implications for intergenerational justice, and in particular for intergenerational inequality, which is an issue in population ethics (Temkin, 1992; Arrhenius and Mosquera, forthcoming; Olsaretti, forthcoming). If population size and welfare are both likely to revert to equilibrium levels, this may reduce intergenerational inequality, or at least the size of the welfare gap between the best-off and worst-off generations. For example, rather than a steady increase or decrease in the average welfare of successive generations over long periods of time, population size and average welfare would instead oscillate between different equilibrium points and different levels of average welfare. Given homeostatic population models, intergenerational inequality may be less of a concern from a long-term perspective, at least in one important respect, insofar as the oscillation between different levels of average welfare across generations would constrain the size of the welfare gap between the best- and worst- off generations.

On the other hand, oscillation between different average welfare levels across generations would seem to guarantee some level of welfare inequality between different generations. It might also result in an outcome that is worse, with respect to intergenerational inequality, than a hypothetical outcome in which welfare reaches a high level and remains at that level over a long period of time. In any case, homeostatic population models are relevant to what we should think the pattern of intergenerational inequality will look like over the long term.

Changes in the age structure of a population also have relevance for intergenerational justice, and more generally for intertemporal population ethics. Populations change through births and deaths, but births add very young people, while people that die are often older (or very young). As such, changes to both the birth rate and the death rate will change the age structure, the proportion of individuals at different ages. Similarly, only some people in a population give birth (individuals that are neither very young nor very old), and the proportion of people in childbearing years will determine how many children are born. A consequence of this is that the proportion of young and old people is unlikely to ever be stable, even if in the long run birth rates and death rates are stable. In other words, all changes in births and deaths will also change the proportion of young and old individuals. Moreover, because humans are productive in the middle of their life and young and old individuals require more care, societies redistribute a large amount of resources across individuals' life courses (e.g., from people in the middle of life to younger and older individuals) in both pre-industrial and contemporary societies (Gurven \& Kaplan, 2006; Lee \& Mason, 2011). Intergenerational (as well as intragenerational) justice may be at least 
partly related to age structure and life course flows of resources. For example, age structure and life course flows of resources are important for discussions of sustainability of pension systems in contemporary societies, as well as the value of having more children in low fertility societies 1(e.g. Cigno \& Werding, 2007; Gál, Vanhuysse, \& Vargha, 2018).

\section{The regulation of population size in historical, modern, and future societies}

In the previous sections, I gave a brief overview of how population size might interact with population growth and technology at a theoretical level. I also discussed four implications of such models for population ethics. Below I will apply this discussion in relation to empirical research on historical and contemporary populations.

Theorists agree that in pre-historic human societies resource availability regulated population size. The very low global population growth rates during the last 50,000 years, with the exception of the last two centuries, is strong evidence for such an assumption. However, we have close to no empirical evidence regarding how actual populations developed in the distant past, although historical agricultural societies and hunter-gatherer populations in the recent past serve as examples of how such populations might have looked. Complicating such inquiries is that even populations that must have had relatively stable population sizes in the past, experienced explosive population growth at the time of contact with Europeans (e.g. the Polynesians on Tikopia (Firth, 1936, 1965), and the !Kung people (Howell, 1979)).

Studies using quantitative data for historical agricultural societies relating population growth to economic variables (Galloway, 1988; Lee, 1987), as well as in-depth studies of societal institutions in pre-industrial populations (Drixler, 2013; Firth, 1965) find that populations respond to resources in a Malthusian fashion. Studies on pre-industrial Europe find that Malthusian relationships were substantial, but that they weakened considerably and disappeared during and after the industrial revolution (or at least were dwarfed by other societal changes). In order for a population to respond in a Malthusian homeostatic way to changing resources, population size must affect welfare (more people causes lower wages), and welfare must affect population growth (higher wages causes higher fertility and survival) (Lee, 1985). In pre-industrial Europe, the former effect was much stronger than the latter, but combined they were important enough to determine long-run population dynamics. As explanatory factors for changes in population in the short term, such 
dynamics had weak explanatory power. Nevertheless, a consistent pressure downwards on population growth when population size was above its long-term trend (and vice-versa) was an inescapable determinant of long-term population developments (Lee, 1985, 1987).

When analysing the relationship between welfare and population growth in contemporary societies, it is important to keep in mind that while homeostatic tendencies may not explain short-term population trends, they may still be important for long-term developments. The demographic transition, for example, might appear to be inconsistent with homeostatic resource regulation relative to certain shorter time scales in which there isn't a clear Malthusian relationship between income variation and demographic rates (Coale \& Watkins, 1986); however such a relationship might appear on a longer time scale. Gradual technological development can either be interpreted as exogenous increases of equilibrium level between population and population growth, or as an endogenous process in which larger population sizes contributed to population growth.

Malthus wrote about different "checks" on population. Preventive checks regulate fertility and entry to sexual unions (age at marriage), and positive checks are related to catastrophic mortality and disease related to shortages of resources. The Northwest European marriage pattern has been described as Malthusian in that when economic resources were plentiful men and women marred earlier and the proportion of those who never married decreased. This has been described as the most important way in which demographic rates were related to resources in for example pre-industrial England (Wrigley \& Schofield, 1981). Mortality rates also increased when resources decreased. However, perhaps the most important determinant of population variation was epidemic disease largely exogenous to population size, of which the Black Death in $14^{\text {th }}$ century Eurasia is the most well-known case. The role of sudden and unpredictable mortality, and fertility which responded positively to a reduction in population size (and negatively to increases in population size) suggests that fertility was regulating populations in more predictable ways than mortality (Livi-Bacci, 2007).

However, after and during the industrial revolution the traditional relationship between economic growth (and average welfare) and population growth changed dramatically. For the first time, the rate of technological and economic growth, and the increase in living standards (average welfare) outpaced population growth (though population growth was still higher than ever). As both average welfare and population growth increased simultaneously, and at an increasing pace until the 1960s, a broad Malthusian homeostatic 
interpretation of this period is not possible. This is one reason that factors other than macrolevel trends in welfare have dominated explanations of trends in and determinants of mortality, fertility, and marriage, in the social sciences for contemporary societies. It is not possible to understand the fertility transition, the great decline in fertility in the $19^{\text {th }}$ and $20^{\text {th }}$ centuries, in Malthusian terms, as welfare increased greatly at the same time as fertility fell (the opposite of what a Malthusian model predicts). However, the fertility transition can be interpreted in broader homeostatic terms as a way for a population to regain population balance (and as a response to very high population growth).

Today, most people live in societies where the vast majority of mortality takes place at postreproductive ages (United Nations Population Division, 2017). In such a context, fertility is the dominant determinant of population growth. Mortality after age 45 is not at all related to the Net Reproductive Rate (NRR), or generational replacement. When mortality during and before reproductive ages is low, the difference in population growth between the fertility levels which maintains a stable population (just above 2 children per women) and levels of fertility in high-fertility societies is very substantial. Furthermore, in many populations in the world today the fertility rates are lower than replacement level fertility, and roughly half of the world population between 2010 and 2015 lived in countries with a Total Fertility Rate (TFR) that implied long-term population decline (United Nations Population Division, 2015). As such, fertility dynamics are clearly the major determinant of population dynamics in contemporary and future societies. From the individual perspective, it seems clear that people could, if they wanted, have more surviving children than they choose to have (though this may affect their individual welfare negatively). This seems to be the case for most people in the world today. This suggests that individual agency and childbearing preferences are the primary determinants of future population size. Individuals on average seem to, at some level, coordinate their fertility decisions with expectations of other aspects of life, and on average choose fewer children as they judge that the economic, personal, or societal costs of higher childbearing are undesirable. Whether global fertility levels will converge at a level that is above or below replacement levels seems critical for future population dynamics and the future of human population systems.

Overall, contemporary societies are still characterized by great variance in fertility, both across and within countries. With respect to welfare and fertility, there are many patterns that coexist that may appear contradictory. When examining how population level fertility is affected by the economy and business cycle the relationship is pro-cyclical relationship, meaning that fertility tends to increase in times of economic expansion and decrease in 
times of recession (Sobotka, Skirbekk, \& Philipov, 2011). At the same time, there is a robust cross-sectional association where countries with high fertility have lower wealth, though this relationship may reverse at very high levels of national wealth (Myrskylä, Kohler, \& Billari, 2009). Within pre-industrial societies, wealthy individuals traditionally have had higher fertility than poorer individuals have had. This trend partly reversed during industrialization and during the $20^{\text {th }}$ century. During these times, in many societies the relationship between individual wealth and fertility was negative (Skirbekk, 2008). However there is increasing evidence that in some high-income contemporary societies we once again see a positive wealth-fertility association where richer individuals have more children (e.g. Andersson, 2000; Jalovaara et al., 2019; Kolk, 2019; Kolk \& Barclay, 2019).

How fertility will respond to welfare is critical for understanding the future of human population systems. At large population sizes, it seems inevitable that a broadly Malthusian link between welfare and population growth must exist, i.e. that at some point population size will reduce population growth and cap population size. From what we know about human population systems and estimates of the carrying capacity of Earth this will most likely be achieved without catastrophic drastic population change. Instead, gradually, humans will choose to have fewer children when they face resource constraints (cf. Cohen, 1996). While a large number of children today might be affordable given how much richer we are today than in the past, children are still very costly as a share of parents' income (Kolk, 2021). Economists have suggested that the relative opportunity costs of having children have increased with increasing investment in education, and that this can explain declines in fertility (Becker \& Lewis, 1974). If, globally, people eventually desire fewer children than what is necessary for replacement at current or future higher levels of development, then a shrinking and not an expanding population will be an important determinant of population size and average welfare. Under such circumstances, Boserupian relationships will be more relevant than Malthusian relationships for the relation between welfare and population growth.

To explain current fertility variation within and across populations remains a challenge to contemporary demographers, though from the empirical observations discussed above it is still possible to draw inferences for the future. The most straightforward conclusion is that if fertility remains above the replacement rate, the human population will at some point encounter resource limits that will bound the size of human populations ${ }^{20}$. At population

\footnotetext{
${ }^{20}$ Even making wild hypothetical thought experiments such as interplanar travel does not change such boundaries fundamentally (Hardin, 1959)
} 
sizes close to these limits welfare will be lower. Population growth in all societies has often, during certain periods, had population growth rates of at least 1\%, given socioeconomic circumstances that are harsher than what contemporary individuals face. Such population growth rates are impossible in the medium to long range, given the nature of exponential growth. Therefore, if future fertility levels remain above replacement rates, some homeostatic mechanism is a necessity. We can also be largely certain that any such mechanism will be related to fertility, as any increases mortality will not substantively affect population growth. ${ }^{21} \mathrm{We}$ are also unlikely to run out of the resources that make human life possible (Cohen, 1996), so the homeostatic mechanism regulating population is almost certain to be economic welfare. At some point a continuously growing population will be treated as an unacceptable trade-off against a higher quality of life.

If humans will desire fewer children than what is necessary to maintain population size, minimum population sizes required for maintaining current technological levels will become a more important determinant for any relationship between population size and population growth. If highly developed future societies will tend to be characterized by below replacement level fertility preferences, the amount of government-induced transfers from non-parents towards parents might be one of the most important determinants of future population size and growth. If future populations will be shrinking, and the relationship between population size and welfare is primarily Boserupian, population decline will reduce future welfare.

\section{Conclusions}

In this chapter, I discussed both theoretical as well as empirical evidence for the claim that population size and population growth are endogenously related. The broad theories relating welfare with population change might have weak short-term predictive power but are almost certain to be important over longer time perspectives. As population ethics often takes a long-term perspective, understanding and engaging with demographic theory may be very productive. Even very general models of how population change responds to welfare, and vice versa, may change analytical models in applied population ethics substantially. The broad Malthusian and Boserupian relationships described in this chapter

\footnotetext{
${ }^{21}$ For example, the great famines of the $20^{\text {th }}$ century such as in China in the early 1960 s and in Bengal in the 1940s had relatively little effect on long and medium term population developments.
} 
are a useful starting point. Demographic theory provides a framework for thinking about how population change, population size, and welfare are related.

I provided four concrete examples of the potential usefulness of demographic theory for population ethics. First, a more nuanced discussion of possible positive (Boserupian) as well as negative (Malthusian) effects of additional people on welfare can inform population ethics. While many population ethicists worry about the negative effects on average welfare of increasing population size, growth, and concentration, consistent with Malthusian models, there is far less discussion of the possible positive effects of increasing population size, growth, and concentration on average welfare, consistent with Boserupian models ${ }^{22}$. Second, strong predications from demographic theory may help population ethicists evaluate different scenarios as more or less empirically and theoretically plausible for actual human populations. This would be particularly useful when population ethics is applied to contemporary policy concerns, but may also be useful when considering how much weight to give to a particular theory under conditions of evaluative or normative uncertainty. For example, I argued that the scenario that Parfit describes, in which steadily increasing population size over the long term leads to an extremely large population in which average welfare is extremely low, is very unlikely as it is inconsistent with homeostatic population models. Third, I argued that from the standpoint of demographic theory, absolute human extinction resulting from gradual processes such as resource depletion or climate change is a very unlikely occurrence. Those concerned with reducing extinction risk may therefore have more reason to focus on sudden discrete catastrophic events. Fourth, I argued that homeostatic population models are relevant for how we think about intergenerational inequality over the long term. Rather than steady increases or decreases in the average welfare and population size of successive generations, it is more likely that average welfare and population size will oscillate around different levels of some equilibrium welfare.

While certain insights from demographic discourse are largely absent from debates in population ethics, the opposite is also true. That is, many insights from population ethics are largely absent in demographic discourses. This is particularly true regarding perspectives on future generations and intergenerational issues, many of which are central in economic demography, but seldom considered in the ways population ethicists approach these issues. Deeper engagement with demographers and population ethicists on these issues may provide new insights.

\footnotetext{
${ }^{22}$ An exception can be found in Greaves (this volume).
} 


\section{Acknowledgments}

I want to thank Timothy Campbell for helpful comments and edits. fFinancial support from from Riksbankens Jubileumsfond (grant M17-0372:1 and P17-0330:1) is gratefully acknowledged.

\section{References}

Andersson, G. (2000). The impact of labour-force participation on childbearing behaviour: procyclical fertility in Sweden during the 1980s and the 1990s. European Journal of Population, 16(4), 293-333.

Arrhenius, G. (2011). The Impossibility of a Satisfactory Population Ethics. In E. N. Dzhafarov \& L. Perry (Eds.), Descriptive and Normative Approaches to Human Behavior (pp. 1-26). Singapore: World Scientific.

Arrhenius, G., \& Campbell, T. (2017). The Problem of Optimal Population Size”. In M. Fleurbay (Ed.), International Panel on Social Progress 1st Annual Report.

Becker, G., \& Lewis, H. G. (1974). Interaction between quantity and quality of children. In T. W. Schultz (Ed.), Economics of the family: Marriage, children, and human capital (pp. 81-90). Cambridge, MA: National Bureau of Economic Research.

Bengtsson, T., Campbell, C., \& Lee, J. Z. (2003). Life under pressure: Mortality and living standards in Europe and Asia, 1700-1900. Cambridge, MA: The MIT Press.

Boserup, E. (1965). The conditions of agricultural growth : the economics of agrarian change under population pressure. London: Allen \& Unwin.

Boserup, E. (1981). Population and technology. Oxford: Blackwell.

Broome, J. (1996). The welfare economics of population. Oxford Economic Papers, 48(2), 177-193.

Broome, J. (2010). The most important thing about climate change. In J. Boston, A. Bradstock \& D. Eng (Eds.), Public Policy: Why Ethics Matters (pp. 101-116): ANU E Press.

Charbonneau, H., Desjardins, B., Légaré, J., \& Denis, H. (2000). The population of the StLawrence Valley, 1608-1760. In M. R. Haines \& R. H. Steckel (Eds.), A population history of North America (pp. 99-142). Cambridge: Cambridge University Press.

Chu, C. C., \& Tsai, Y.-C. (1998). Productivity, investment in infrastructure and population size: formalizing the theory of ester boserup Increasing returns and economic analysis (pp. 90107): Springer.

Cigno, A., \& Werding, M. (2007). Children and pensions. Cambridge, MA: MIT Press.

Coale, A. J., \& Watkins, S. C. (1986). The decline of fertility in Europe : the revised proceedings of a Conference on the Princeton European Fertility Project. Princeton, N.J.: Princeton University Press.

Cohen, J. E. (1996). How many people can the earth support? New York: Norton.

Courchamp, F., Clutton-Brock, T., \& Grenfell, B. (1999). Inverse density dependence and the Allee effect. Trends in ecology \& evolution, 14(10), 405-410.

Dasgupta, P. (1998). Population, consumption and resources: ethical issues. Ecological Economics, 24(2), 139-152. 
Drixler, F. F. (2013). Mabiki: Infanticide and Population Growth in Eastern Japan, 1660-1950

Berkeley: University of California Press.

Firth, R. (1936). We, the Tikopia. London: George Allen \& Unwin.

Firth, R. (1965). Primitive Polynesian economy. London.

Gál, R. I., Vanhuysse, P., \& Vargha, L. (2018). Pro-elderly welfare states within child-oriented societies. Journal of European Public Policy, 25(6), 944-958.

Galloway, P. R. (1988). Basic patterns in annual variations in fertility, nuptiality, mortality, and prices in pre-industrial Europe. Population studies, 42(2), 275-303.

Ghirlanda, S., \& Enquist, M. (2007). Cumulative culture and explosive demographic transitions. Quality \& quantity, 41(4), 591-600.

Ghirlanda, S., Enquist, M., \& Perc, M. (2010). Sustainability of culture-driven population dynamics. Theoretical Population Biology, 77(3), 181-188. doi: DOI 10.1016/j.tpb.2010.01.004

Gurven, M., \& Kaplan, H. (2006). Determinants of time allocation across the lifespan. Human nature: an interdisciplinary biosocial perspective, 17(1), 1.

Hardin, G. (1959). Interstellar migration and the population problem. Journal of Heredity, 50(2), 68-70.

Howell, N. (1979). Demography of the Dobe !Kung. New York: Academic Press.

Hutchinson, E. P. (1967). The population debate : The development of conflicting theories up to 1900. Boston: Houghton Mifflin.

Jalovaara, M., Neyer, G., Andersson, G., Dahlberg, J., Dommermuth, L., Fallesen, P., \& Lappegård, T. (2019). Education, gender, and cohort fertility in the Nordic countries. European Journal of Population, 35, 563-586. doi: 10.1007/s10680-018-9492-2

Kolk, M. (2019). The relationship between lifecourse accumulated income and childbearing of Swedish men and women born 1940-1970. Stockholm Research Reports in Demography, 2019:19.

Kolk, M. (2021). Government transfers to parents and population policy in a global perspective: An economic demographic approach. Journal of Development Studies, forthcoming.

Kolk, M., \& Barclay, K. (2019). Cognitive ability and fertility among Swedish men born 19511967: evidence from military conscription registers. Proceedings of the Royal Society B: Biological Sciences, 20190359. doi: 10.1098/rspb.2019.0359

Lee, R. (1985). Population homeostasis and English demographic history. The Journal of Interdisciplinary History, 15(4), 635-660.

Lee, R. (1986). Malthus and Boserup: a dynamic synthesis. In D. A. Coleman \& R. S. Schofield (Eds.), The State of population theory: forward from Malthus. Oxford: Blackwell.

Lee, R. (1987). Population dynamics of humans and other animals. Demography, 24(4), 443-465.

Lee, R., \& Anderson, M. (2002). Malthus in state space: Macro economic-demographic relations in English history, 1540 to 1870. Journal of Population Economics, 15(2), 195-220.

Lee, R., \& Mason, A. (2011). Population aging and the generational economy: a global perspective. Cheltenham: Edward Elgar.

Lehmann, L., Aoki, K., \& Feldman, M. W. (2011). On the number of independent cultural traits carried by individuals and populations. Philosophical Transactions of the Royal Society B: Biological Sciences, 366(1563), 424-435.

Livi-Bacci, M. (1999). The population of Europe : a history. Malden, MA: Blackwell. 
Livi-Bacci, M. (2007). A concise history of world population. Oxford: Blackwell.

Myrskylä, M., Kohler, H.-P., \& Billari, F. C. (2009). Advances in development reverse fertility declines. Nature, 460(7256), 741-743.

Parfit, D. (1984). Reasons and persons. Oxford: Clarendon Press.

Pryor, F. L., \& Maurer, S. B. (1982). On induced economic change in precapitalist societies. Journal of Development Economics, 10(3), 325-353.

Sibly, R. M., \& Hone, J. (2002). Population growth rate and its determinants: an overview. Philosophical Transactions of the Royal Society B: Biological Sciences, 357(1425), 1153-1170.

Simon, J. L. (1977). The economics of population growth. Princeton (N.J.). Princeton University Press.

Skirbekk, V. (2008). Fertility trends by social status. Demographic Research, 18(5), 145-180.

Sobotka, T., Skirbekk, V., \& Philipov, D. (2011). Economic recession and fertility in the developed world. Population and development review, 37(2), 267-306.

Tsuya, N., Feng, W., Alter, G., \& Lee, J. Z. (Eds.). (2010). Prudence and pressure. Cambridge: MIT Press.

United Nations Population Division. (2015). World Fertility Repord 2015 - data booklet. New York: (United Nations publication).

United Nations Population Division. (2017). World Mortality Report 2015. New York: (United Nations publication).

Wilson, C., \& Airey, P. (1999). How can a homeostatic perspective enhance demographic transition theory? Population Studies, 53(2), 117-128.

Wrigley, E. A., \& Schofield, R. S. (1981). The population history of England 1541-1871 : a reconstruction. London: Arnold. 